\title{
ISSN 0925-854X
}

\section{OFFPRINT FROM}

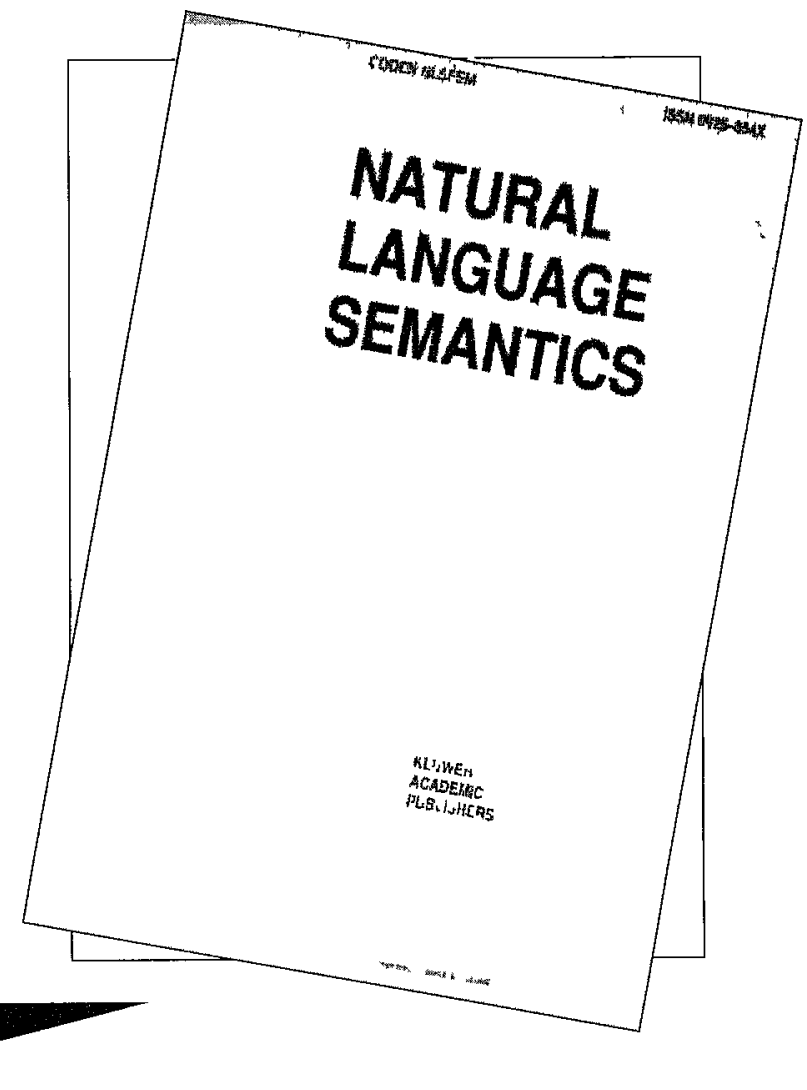

Remember the Library! they need your suggestions to service your needs

\section{Kluwer} academic publishers

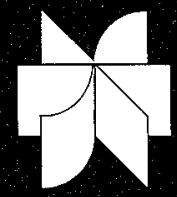




\section{Natural Language Semantics}

An International Journal of Semantics and Its Interfaces in Grammar

\section{Editors:}

Irene Heim

MIT, Cambridge, MA, USA

Angelika Kratzer

University of Massachusetts, Amherst, USA

\section{Editorial Assistant: \\ Christine Bartels}

\section{Editorial Board:}

Mark Baker, McGill University, Gennaro Chierchia, University of Milan, David Dowty, Ohıo State University, Mürvet Enç, University of Wisconsın-Madison, Elisabet Engdahl, University of Edinburgh, Jane Grimshaw, Rutgers University, Jeroen Groenendijk, University of Amsterdam, James Higginbotham, MIT, Hajime Hoji, University of Southern California, James Huang, University of California, Irvine, Hans Kamp, University of Stuttgart; Richard Larson, State University of New York at Stony Brook; Giuseppe Longobardi, University of Venice, Robert May, University of California, Irvine, James McCloskey, University of Callfornia, Santa Cruz, Stephen Neale, University of Callfornia, Berkeley, Taisuke Nishigauchi, Osaka University; Barbara Partee, Unversity of Massachusetts, David Pesetsky, MIT, Tanya Reinhart, Tel AvIV University, Mats Rooth, University of Stuttgart, Martin Stokhof, University of Amsterdam, Anna Szabolcsi, University of Callfornia, Los Angeles, Arnim von Stechow, University of Tubingen

Natural Language Semantics is devoted to semantics and its interfaces in grammar, especially syntax The journal seeks to encourage the convergence of approaches employing the concepts of logic and philosophy with perspectives of generative grammar on the relatıons between meaning and structure

Natural Language Semantics publishes studies focused on linguistic phenomena as opposed to those dealing primarily with the field's methodological and formal foundations Representative topics include, but are not IImited to, quantification, negation, modality, genericity, tense, aspect, aktıonsarten, focus, presuppositions, anaphora, definıteness, plurals, mass nouns, adjectıves, adverbıal modification, nomınaiızation, ellipsis, and Interrogatives

The journal features mainly research articles, but also short squibs as well as remarks on and replies to pertinent books and articles Natural Language Semantics is abstracted in Sociological Abstracts, Linguistic Bibliography, INSPEC Information Services, Linguistics Abstracts 


\title{
TWO TYPES OF DONKEY SENTENCES*
}

\begin{abstract}
Mandarin Chinese exhıbits two paradigms of conditionals with indefinite $w h$-words that have the semantics of donkey sentences, represented by 'bare conditionals' on the one hand and ruguo- and dou-conditionals on the other The bare conditionals require multiple occurrences of $w h$-words, disallowing the use of overt or covert anaphoric elements in the consequent clause, whereas the ruguo- and dou-conditionals present a completely opposite pattern We argue that the bare conditionals are cases of unselective binding par excellence (Heim 1982, Kamp 1981) while the ruguo- and dou-conditionals are most naturally accounted for with the traditional Etype pronoun strategy of Evans (1980). We thus argue partly for a return to the E-type strategy (along with Heim 1990) but maintain the need for unselective binding in UG (cf. Kratzer 1989, Chierchia 1992) It is further shown that these two paradigms do not differ with respect to the proportion problem and the distribution of symmetric and asymmetric readings of Kadmon (1987), though they differ with respect to $\forall$ and $\exists$ readings (discussed in Chierchia 1992) in a non-trivial way that provides further support for the proposed approach. Finally, evidence is given that the bare conditionals should be kept apart from correlative constructions in languages like Hind, and treated differently from the latter
\end{abstract}

\section{INTRODUCTION}

The treatment of donkey sentences has been the center of much debate since the topic was introduced to lingussts in the early ' 80 s. Central to this debate is the question of the status of the pronouns and the indefinite NPs with which they are related in a sentence like (1):

If a man owns a donkey, he beats it.

Take the pronoun $t t$, for example. It has an indefinite NP as its "antecedent,"

* Various versions of this paper were presented at NACCL 4 at the University of Delaware, NELS 24 at UMass Amherst, the Conference on the Robustness of the Language Faculty at the University of Utrecht, and at colloquia at UCLA, Oh1o State University, and the University of Oslo, the Chinese University of Hong Kong, National Tsing Hua University, and the University of Britısh Columbia. We thank the audiences at these occasions for their valuable comments and useful suggestions For the pleasant opportunity to discuss the materials with them, we are partıcularly indebted to Irene Hetm, Gennaro Chierchia, Denis Delfitto, Viviane Deprez, Molly Diesing, Ken Halc, Christoph Harbsmeier, Ming-yang Hu, Utpal Lahırı, Jowang Lin, Anoop Mahajan, K P Mohanan, Friederike Moltmann, Waltraud Paul, Marie-Claude Parıs, Davıd Pesetsky, Tim Stowell, Anna Szabolscı, and We1-tıen Tsa1 We would also like to thank two anonymous reviewers for their detaled comments and suggestions During the research reported here, $J$ Huang was supported in part by an NSF grant, \#SBR-9121167. 
which, on the traditional Russellian analysis, is an existential quantifier. However, it is not a true bound variable because as an existential quantifier the indefinite NP in the antecedent clause clearly does not have scope over it and hence cannot bind it. Two prominent solutions to this paradox have been proposed. Evans (1980) adopted the Russellian view of the indefinite as a quantifier and denied the bound-variable status of the pronoun. Heim (1982) and Kamp (1981), on the other hand, developed an alternative theory, within the framework of their Discourse Representation Theory (DRT), which maintains the bound-variable status of the pronoun, but denies the status of the indefinite as an existential quantifier. According to Evans (1980), the pronouns he and it in (1) belong to a distinct category, called E-type pronouns, whose status is more on a par with definite descriptions than true variables (see also Cooper 1979 and Parsons 1978 for earlier suggestions to the same effect). The role played by the E-type pronouns is that of referring "to the object(s), if any, which verify the antecedent quantifier-containing clause" (p. 340). According to this analysis, a sentence such as (2a) can be interpreted as $(2 \mathrm{~b})$ :

(2) a. If a man enters the room, he will trip the switch.

b. If a man enters the room, the man who enters the room will trip the switch.

Evans uses the sentences in (3a) and (3b) to show a clear contrast between bound pronouns and E-type pronouns:

(3) a. Few congressmen admire only the people they know.

b. Few congressmen admire Kennedy, and they are very junior.

The pronoun they in ( $3 \mathrm{a}$ ) is bound by the quantifier phrase few congressmen which c-commands it. In contrast, the pronoun they in (3b) is not bound by the quantifier phrase since the latter does not c-command the former. Further, the interpretation of the sentences clearly shows that the pronoun they in (3b) is not a bound pronoun. (3b) entails two things: (i) few congressmen admire Kennedy, and (ii) all the congressmen who admire Kennedy are very junior. However, if the pronoun is interpreted as a bound pronoun, the reading will be "Few congressmen both admire Kennedy and are very junior." According to this reading, there can be many congressmen who admire Kennedy, though only a few of them are junior. This is not a reading available to (3b).

Evans shows that an E-type pronoun cannot take a negative quantifier like no one, nobody as its antecedent: ${ }^{1}$

There are some apparent counterexamples to this claim, as pointed out by the reviewers: 
(4) a. No congressmen admire only the people they know.

b. * No congressmen admire Kennedy, and they are very junior.

(5) a. No donkey likes a farmer to beat it.

b. ${ }^{*}$ If a farmer owns no donkey, he beats it.

This is a natural consequence of the E-type analysis, since the meaning of an E-type pronoun is simply not compatible with having a negative quantificational expression as an antecedent. As Evans states, E-type pronouns refer to "the objects that verify the antecedent quantifier-containing clause," and "the truth of the clause containing them requires that all the relevant objects satisfy the predicate, ..." In the case of the quantifier no donkey, no member of the set $\{\mathrm{x} \mid$ donkey $(\mathrm{x})\}$ satisfies the antecedent predicate, so a pronoun (as a definite description, which presupposes the existence of at least one member that satisfies the predicate) is inappropriate. For a similar reason, this analysis explains why an E-type pronoun must take the plural form if the antecedent is a universal quantifier, though this is not required of a true bound variable:

(6) a. Every donkey fears that its/?their owner will beat it/?them.

b. If a farmer owns every donkey, he will beat them/*it.

Since there is no unique donkey that can alone make the antecedent clause true in (6b), a singular pronoun or definite description (which presupposes the existence of such a singleton set) is inappropriate.

In Evans' analysis, the indefinite antecedent of a donkey pronoun is treated as a standard quantifier, much as quantifiers like no one, everyone are. The donkey pronoun itself is treated in a unified way regardless of the quantificational type of its antecedent.

In the DRT analysis of Kamp (1981) and Heim (1982), on the other hand, an indefinite NP such as a donkey or a farmer is taken to be something

(i) No one came. They all stayed home.

(ii) I saw no first-year student at the meeting. They went to the party instead.

Compare (iii) with the example in (4b):

(iii) No congressmen admire Kennedy. They all admire Jefferson.

The contrast between (iii) and (4b) in fact shows that the pronoun in (iii) is not an E-type pronoun. The E-type pronoun in (4b) has the denotation 'the congressmen who admire Kennedy'; this set is null and thus the sentence is ungrammatical. In other words, the pronoun they takes no one as its antecedent. Now consider the pronoun in (iii). It does not have the same denotation. Instead, it denotes 'the congressmen who do NOT admire Kennedy', which is not a null set. That is, the pronoun they in this case does not take no one as its antecedent. Hence, the examples here are not counterexamples to Evans' claim. 
without inherent quantificational force, as it exhibits quantificational variability under adverbs of quantification (Lewis 1975). Thus the indefinites in (1) may appear to have the quantificational force of all, most, and some in the context of always, usually, and sometimes, respectively:

(7) Always, if a farmer owns a donkey, he beats it. $=$ All farmers $(\mathrm{x})$ and donkeys $(\mathrm{y})$ are such that if $\mathrm{x}$ owns $\mathrm{y}$, then $x$ beats $y$.

(8) Usually, if a farmer owns a donkey, he beats it. $=$ Most farmers ( $\mathrm{x})$ and donkeys (y) are such that if $\mathrm{x}$ owns $\mathrm{y}$, then $\mathrm{x}$ beats $\mathrm{y}$.

(9) Sometimes, if a farmer owns a donkey, he beats it.

$=$ Some farmers $(\mathrm{x})$ and donkeys $(\mathrm{y})$ are such that $\mathrm{x}$ owns $\mathrm{y}$, then $\mathrm{x}$ beats $\mathrm{y}$.

According to the DRT analysis, the indefinite is taken not to be a quantifier, but itself a variable bound by an adverb of quantification, from which it derives its quantificational force. In the absence of an overt adverb of quantification, Heim assumes that both the indefinites (qua variables) and the pronouns (also variables) are unselectively bound by an implicit necessity operator associated with conditionals, which expresses conditional necessity and contributes universal force. The pronouns share the same index as the indefinite NPs and are thus anaphorically related to them:

$$
\text { Necessarily }_{1,} \text {, if a farmer } \text { owns a donkey }_{j} \text {, he } e_{1} \text { beats it. }
$$

Given the universal force of the necessity operator, the interpretation of the sentence can be represented as in (11):

$$
\begin{aligned}
& \forall \mathrm{x} \forall \mathrm{y}((\mathrm{x} \text { is a man \& } \mathrm{y} \text { is a donkey \& } \mathrm{x} \text { owns } \mathrm{y}) \rightarrow \mathrm{x} \text { beats } \\
& \mathrm{y})
\end{aligned}
$$

In the Heim-Kamp approach, then, not only the pronouns but also the indefinites that antecede them are treated as true bound variables. It is worthwhile to note that only indefinites and the donkey pronouns that take indefinite antecedents are treated as bound variables. Inherent quantifiers like everyone, no one are still treated as generalized quantifiers in the standard way, and donkey pronouns that are related to them (e.g. everyone) would presumably still be treated along some variant of an E-type analysis. In other words, there is no unified treatment of the donkey pronoun across the various quantification types of its antecedents.

There has been considerable research on the issue since the debate was introduced more than a decade ago. Some important problems facing these 
proposals were discussed by Kadmon $(1987,1990)$, Pelletier and Schubert (1989), and Neale (1991). More recently, HeIm (1990) herself showed that some of the problems posed by an E-type analysis of donkey pronouns are in fact solvable within the same analysis (augmented by the concept of minimal situation), ${ }^{2}$ and that unselective binding does not fare better than an E-type analysis in solving certain problems. ${ }^{3}$ Heim (1990) then argues, in effect, for a return to the traditional E-type analysis. On the other hand, there are two proponents of a mixed approach, namely Kratzer (1989) and Chierchia (1992). Kratzer (1989) shows that the 'proportion problem' brought about by the Kamp-Heim approach can be solved by the E-type strategy. However, the E-type strategy leads to the uniqueness problem. To solve the problem associated with the E-type strategy, Kratzer proposes a mixed analysıs which utilizes the Kamp-Heim approach withın the Etype strategy (see Kratzer 1989 for details). Chierchia (1992) develops a dynamic binding approach, which also has the property of mixing a KampHerm approach and the E-type pronoun strategy.

In this paper, we investigate conditional sentences with donkey anaphora in Mandarın Chinese and show that two distinct types of conditional donkey sentences must be recognized. We argue that the first type of donkey sentence (the bare conditionals) is a case of unselective binding par excellence, whereas the other type (the ruguo- and dou-conditionals) is best analyzed in terms of an E-type analysis - as the two types exhibits

\footnotetext{
2 Although the property of quantificational variability under adverbs of quantification has often been taken to be the main argument for unselective binding (Nishigauchı 1990, Diesing 1992, etc ), the real argument, as Heim (1990) points out, hes in the fact that an E-type analysis of a donkey pronoun carries with it a uniqueness presupposition, given Russell's analysis of definite descriptions as entailing both existence and uniqueness The problem occurs with sentences like (1)
}

If a man is in Athens, he is not in Rhodes

The E-type analysis of he entarls that for the sentence to be false, there has to be a unique man in Athens who is also in Rhodes But under this interpretation the sentence will always be true (or without a truth value) since there is no unique man in Athens This interpretation is clearly wrong, as speakers have no problem identifying the truth conditions of the sentence it is false if any man is ever found to be both in Athens and Rhodes and true otherwise.

HeIm (1990) shows that the problem of unıqueness presupposition can be overcome by the assumption that there is quantification over minimal events (situatıons) in the matrix clause, in addition to existential quantification, within the E-type analysis, in the embedded antecedent clause. Thus, ( 1 ) is interpreted as "For every minimal situation where exactly one man is in Athens, there cannot be another minimal situation where the unique man in Athens is also in Rhodes"

3 For example, both approaches face the 'proportion problem', discussed below in section 
properties that respectively match the predictions made by these two approaches in great detail. The evidence presented here sheds light on the current debate regarding donkey anaphora. Our conclusion is that both unselective binding and E-type strategies are justified for natural language (and hence also both the notion of an indefinite as a variable and the notion of it as a generalized quantifier), but perhaps not for the types of constructions that have been studied in English. We concur with Heim (1990) that an E-type analysis would be appropriate (with certain augmentations as has been suggested) for the type of conditional donkey sentences that have been considered in English, but argue that there is also reason to resurrect the analysis of unselective binding she proposed in Heim (1982). In this respect our conclusion concurs with that of Kratzer (1989) and Chierchia (1992) in spirit, though it should be clear later that our approach is not strictly 'mixed', particularly when the first type of donkey sentences are considered. In line with recent works, we show that the unselective binding strategy does not differ from the E-type strategy with respect to the proportion problem and the distribution of 'symmetric' and 'asymmetric' readings (Kadmon 1987, 1990, inter alia) as it shows up in both kinds of donkey sentences in Chinese. Furthermore, the distribution of the $\forall$ vs. $\exists$ reading (as discussed in Chierchia 1992) clearly distinguishes the bare conditionals from the ruguo-conditionals. Finally, we briefly consider a tempting alternative to assimilate the bare conditionals to correlative constructions in languages like Hindi, but show that the assimilation is undesirable on the level of syntactic analysis, as they belong to very different species.

\section{Donkey Sentences in Chinese}

In Mandarin Chinese, conditional sentences with the appearance of donkey sentences may involve a wh-word in the antecedent clause and something anaphoric to it in the consequent clause. Mandarin exhibits three such types on the surface: bare conditionals, dou-conditionals, and ruguo-conditionals. These three types fall into two descriptive paradigms: the bare conditionals on the one hand, and the dou- and ruguo-conditionals on the other. As we shall see, these two paradigms exhibit complementary properties, in that donkey anaphora in the former can only take the form of a $w h$-word in the consequent clause, disallowing all other forms, whereas the latter excludes just wh-words from serving as donkey pronouns, permitting all other anaphoric forms. 


\subsection{Bare Conditionals}

'Bare Conditionals' are conditionals which do not have an overt leading element such as ruguo 'if' in the antecedent clause or an overt quantifier such as dou 'all' in the consequent clause. ${ }^{4}$ In this type of conditionals, the word jiu 'then' is optionally present in the consequent clause, as we can see in (12).

(12) a. shei xian lai, shei xian chi who first come, who first eat 'If X comes first, $\mathrm{X}$ eats first.'

b. shei xian lai, shei jiu xian chi who first come, who then first eat 'If $\mathrm{X}$ comes first, then $\mathrm{X}$ eats first.'

We see in (12) that the presence or absence of jiu 'then' does not entail any difference in interpretation. There are two $w h$-words in the sentence, one in the antecedent clause, the other in the consequent clause. As indicated in (13), the wh-word in the consequent clause cannot be replaced by an overt pronoun (13a), a null pronoun (13b), or a definite NP (13c). ${ }^{5}$ Furthermore, there must be an element that can refer back to the $w h$-word in the antecedent clause, or the sentence would be ill-formed, as in (13d). The sentences in (14) show the same point as (13a) through (13d); they differ only with respect to the location of the $w h$-word and the anaphoric elements under consideration.

$$
\begin{aligned}
& \text { Subject-Subject } \\
& \text { a.* shei xian lai, ta xian chi } \\
& \text { who first come s/he first eat } \\
& \text { b.* shei xian lai, [e] xian chi } \\
& \text { who first come first eat } \\
& \text { c.* shei xian lai, na-ge-ren xian chi } \\
& \text { who first come that-CL-person first eat } \\
& \text { 'If X comes first, X eats first.' }
\end{aligned}
$$

\footnotetext{
4 The term "bare conditional" used here differs from the term used in Heim (1982) which refers to conditional sentences in English without any overt adverb of quantification. Crucially, 'if' is present in such conditionals in English. In Mandarin Chinese, the bare conditionals are bare in that there is no leading element such as 'if' in the antecedent clause.

5 Chinese is a language which allows null subjects and objects.
} 
d.*shei xian lai, wo bu gaoxing who first come I not happy

'If X comes first, I will be unhappy.'

(14) Object-Object

a. ni xihuan shei, wo jiu piping shei you like who I then criticize who

'If you like X, I then criticize X.'

b.*ni xihuan shei, wo jiu piping ta you like who I then criticize him/her

c. ${ }^{*}$ ni xihuan shei, wo jiu piping [e] you like who I then criticize

d.*ni xihuan shei, wo jiu piping na-ge-ren you like who I then criticize that-CL-person

e.*ni xihuan shei, wo bu gaoxing you like who I not happy

'If you like X, I will be unhappy.'

Sentences (15) and (16) are additional examples showing that even when the $w h$-words do not occur in parallel positions (e.g. subject-subject, object-object), the pattern observed above still holds.

(15) Subject-Object

a. shei xian jinlai, wo xian da shei who first enter I first hit who 'If X first enters, I will hit X.'

b.* shei xian jinlai, wo xian da ta who first enter I first hit him/her

c.* shei xian jinlai, wo xian da $[e]$ who first enter I first hit

d.*shei xian jinlai, wo xian da na-ge-ren who first enters I first hit that-CL-person

(16) Object-Subject

a. ni xihuan shei, shei daomei you like who who unlucky

'If you like $\mathrm{X}, \mathrm{X}$ is unlucky.' 


$$
\begin{array}{clll}
\text { b.*ni xihuan } & \text { shei, ta daomei } & \\
\text { you like } & \text { who s/he unlucky } & \\
\text { c.*ni xihuan } & \text { shei, }[e] \text { daomei } & \\
\text { you like } & \text { who unlucky } & \\
\text { d.*ni xihuan } & \text { shei, na-ge-ren daomei } \\
\text { you like } & \text { who that-CL-person unlucky }
\end{array}
$$

From the above sentences, it is clear that in bare conditionals, the element which refers back to the $w h$-word in the antecedent clause has to be a whword. Moreover, it has to be an identical $w h$-word: a different $w h$-word that provides a paraphrase is not acceptable, as shown in (17).

$$
\begin{aligned}
& \text { (17) *ni xihuan shei, wo jiu piping shenme ren } \\
& \text { you like who I then criticize what person } \\
& \text { 'If you like X, I will criticize X.' }
\end{aligned}
$$

We have so far given examples of bare conditionals containing only one $w h$-word in the antecedent clause. Note that there can be more than one $w h$-word, and in these cases the consequent clause has to contain the same number of $w h$-words, referring back to the $w h$-words in the antecedent clause.

(18) shei yan shei, shei jiu xiang shei who play who who then resemble who

'If $\mathrm{X}$ plays the role of $\mathrm{Y}$, then $\mathrm{X}$ will resemble $\mathrm{Y}$.'

(19) shei da-puo-le shenme, shei jiu de qu mai shenme who break-ASP what who then must go buy what 'If X broke $\mathrm{Y}$, then $\mathrm{X}$ must buy Y.'

It has been noted by Yu (1965) and Lü (1980) that there are some cases which seem to show a pronoun/wh-word alternation (data from Yu 1965):

(20) a. shei yao zhe puo-chang, wo jiu rang gei who want this broken-factory I then give to

ta/shei

him(her)/who

'Whoever wants this broken factory, I'll give it to him/her.'

b. shei bu dui, wo jiu shuo talshei bu dui who not right I then say he(she)/who not right

'Whoever is not right, I'll say that he/she is not right.' 
We will discuss these examples in section 3.3. For the moment, we observe that in those sentences in which a pronoun/wh-word alternation is possible, the consequent clause must contain the adverbial element jiu 'then'. In the absence of this element, the conditional is "completely bare" and no pronoun/wh-word alternation is possible:

$$
\begin{aligned}
& \text { shei yao zhe puo-chang, wo rang gei shei/*ta. } \\
& \text { who want this broken-factory I give to who/him(her) } \\
& \text { 'Whoever wants this broken factory, I will give it to him/her.' }
\end{aligned}
$$

\subsection{Dou-Conditionals and Ruguo-Conditionals}

Dou-conditionals are characterized by the presence of the quantifier dou 'all' in the consequent clause, whereas ruguo 'if' heads the antecedent clause in the ruguo-conditionals. ${ }^{6}$ These two types of conditionals present an opposite situation from the one we have just seen. The element in the consequent clause which refers back to the $w h$-word in the antecedent clause cannot be a $w h$-word; instead, it must be a pronoun (null or overt) or a definite description. ${ }^{7}$ Furthermore, there need not be anything in the consequent clause referring back to the $w h$-word in the antecedent clause at all.

(22) a.* ni jiao shei jin-lai, wo dou jian shei

you ask who enter I all see who

'Whoever you ask to come in, I'll see him/her.'

b. ni jiao shei jin-lai, wo dou jian ta you ask who enter I all see him/her

'Whoever you ask to come in, I'll see him/her.'

c. ni jiao shei jin-lai, wo dou jian $[e]$

you ask who enter $\mathrm{I}$ all see

d. ni jiao shei jin-lai, wo dou jian na-ge-ren
you ask who enter I all see that-CL-person

6 See section 3.2.2. for a more detailed discussion of dou-conditionals as a species of "unconditionals" discussed in Zaefferer (1990).

7 It appears that the occurrence of a null pronoun is less acceptable than an overt pronoun. We will not discuss the differences in detail because that would lead us to a different topic, namely, the differences between overt and null pronouns, which have been studied at length (see e.g., Huang 1984). 
e. ni jiao shei jin-lai, wo dou bu gaoxing you ask who enter I all not happy

'Regardless of who you ask to enter, I'm not happy.'

(23) a.* ruguo ni kandao shei, qing jiao shei lai jian wo if you see who please tell who come see me 'If you see someone, please ask him/her to come see me.'

b. ruguo ni kandao shei, qing jiao ta lai jian if you see who please tell him/her come see

wo

me

c. ruguo $\mathrm{ni}$ kandao shei, qing jiao [e] lai jian wo if you see who please tell come see me

d. ruguo ni kandao shei, qing jiao na-ge ren if you see who please tell that-CL-person

lai jian wo

come see me

'If you see someone, please ask that person to come see me.'

e. ruguo ni kandao shei, qing gankuai gaosu wo if you see who please quickly tell me

'If you see someone, please tell me quickly.'

In both (22) and (23), the (a) examples with a wh-word in the consequent clause are completely ill-formed. The $(b-d)$ examples with an overt pronoun, a null pronoun, or a definite description that refers back to the wh-element are well-formed. The (e) examples with no anaphoric element in the consequent clause at all are also well-formed. As is evident, these conditionals exhibit striking contrasts with bare conditionals. These contrasts raise a number of questions:

(24) a. Why can bare conditionals host an identical wh-word in the consequent clause but not a pronoun, an empty pronoun, or a definite description?

b. Why do bare conditionals always need an anaphoric element in the cunsequent clause?

c. Why is it the case that the dou/ruguo-conditionals cannot host a $w h$-word in the consequent clause but allow a pronoun or a definite NP? 
d. Why is it the case that the dou/ruguo-conditionals do not need to have an anaphoric element in the consequent clause?

\section{ANALYSIS}

As an attempt to answer the questions posed in (24), we propose that both unselective binding and E-type pronoun strategies are involved in donkey anaphora. In particular, the bare conditionals are cases of unselective binding par excellence, whereas the other two kinds of conditionals have E-type pronouns.

\subsection{Unselective Binding: Bare Conditionals}

The properties exhibited in bare conditionals can be summarized as follows:

(25) Properties of bare conditionals

a. The donkey anaphor must take the form of a $w h$-word.

b. The donkey $w h$-word must be identical to the wh-word in the antecedent clause.

c. There must be an element in the consequent clause referring back to the $w h$-word in the antecedent clause.

To explain this array of properties, we assume, following Cheng (1991, 1995) (cf. Li 1992), that wh-words in Chinese are polarity items - indefinite NPs which do not have inherent quantificational force but instead acquire their quantificational force in context, through the external element(s) that license and/or bind them (see also Heim 1982 and Nishigauchi 1990). In the case of bare conditionals, which lack an overt licenser for $w h$-words, we assume that these are licensed and bound by an implicit necessity operator. Along the lines of Heim's (1982) treatment of indefinites in English, wh-words are treated not as quantifiers but as variables bound by the necessity operator, which in turn gives rise to the force of wide-scope universal quantification. Thus, (12) is interpreted as in (26).

$$
\forall \mathrm{x} \text { (x comes first } \rightarrow \mathrm{x} \text { eats first) }
$$

In other words, the $w h$-word in the antecedent clause and the one in the consequent clause are both directly bound by the necessity operator. The $w h$-words share the same index and are thus anaphorically related to each other. The binding can be truly unselective in that the binder may bind distinct variables simultaneously. In this case the necessity operator has 
the force of a universal quantifier ranging over ordered pairs. The logical representation of (18) is as follows:

$$
\forall \mathrm{x} \forall \mathrm{y} \text { ((x plays the role of } \mathrm{y}) \rightarrow(\text { ( } \text { resembles } \mathrm{y}))
$$

We assume the necessity operator to be the default binder/licenser of the $w h$-words in bare conditionals without an overt adverb of quantification. In those cases where an adverb of quantification is present, the adverb is the binder and licenser, and the quantificational force of the wh-word varies from one adverb to another. Thus the following sentences may be interpreted on a par with quantificational sentences containing determiners like most, some, and few, respectively.

$$
\text { tongchang, shei yan shei, shei jiu xiang shei }
$$
usually who play who who then resemble who 'For most $\mathrm{x}, \mathrm{y}$, if $\mathrm{x}$ plays the role of $\mathrm{y}$, then $\mathrm{x}$ resembles $\mathrm{y}$.'

(29) you-shihou, shei yan shei, shei jiu xiang shei sometimes who play who who then resemble who 'For some $\mathrm{x}, \mathrm{y}$, if $\mathrm{x}$ plays the role of $\mathrm{y}$, then $\mathrm{x}$ resembles $\mathrm{y}$.'

(30) (neixie ren) nande shei yan shei, shei jiu (those people) seldom who play who who then xiang shei
resemble who

'Of those people, it seldom happens that if $\mathrm{x}$ plays the role of $y$, then $x$ resembles $y . '$

One question that may arise is why the $w h$-words cannot be caught by existential closure (Heim 1982, Diesing 1992), thereby obtaining existential force. The answer to this question centers around the properties of wh-words in Chinese. They are polarity items and thus need a licenser. The natural licenser in a bare conditional is the necessity operator. ${ }^{8}$ Thus, the necessity operator in a conditional serves as the polarity licenser and the binder for the $w h$-words. Since the $w h$-words already have a binder, there

8 As Heim (pers. comm.) points out to us, typically in conditionals, only polarity items in the antecedent clause can be licensed. In the bare conditionals in Mandarin Chinese, it appears that $w h$-words can appear in both antecedent and consequent clauses. This indicates that the licensing of the $w h$-words in such cases is not something that is particularly related to the antecedent clause. Note that licenser(s) of particular polarity items may vary even within a language. Thus, it is not the case that all polarity items can be licensed by the necessity operator. 
is no reason to invoke existential closure. The prediction 1s, therefore, that $w h$-words in bare conditionals will not have an existential reading due to the unavailability of the existential closure. ${ }^{9}$

\subsubsection{Obligatory Presence of a Wh-Word in the Consequent Clause}

According to our treatment, bare conditionals with $w h$-words are interpreted by universal quantification (in the default cases) involving an unselective binder that has scope over both the antecedent and consequent clauses. We are now ready to give an explanation for the properties of bare conditionals observed above. One such property is the obligatory occurrence of a $w h$-word in both clauses: the $w h$-words must appear in pairs - if there is one $w h$-word in the antecedent clause, there must be another $w h$-word of the same kind in the consequent clause. And if there are two in the antecedent clause, two $w h$-words must then show up in the consequent clause. Conversely, if we only find $w h$-words in the consequent clause but not in the antecedent clause, the result is also ungrammatical. Thus, the question in (24b) can be further specified as: why is it the case that the wh-words must appear in pairs? We suggest that this question can be answered under the following two assumptions from DRT: ${ }^{10}$

(31) a. Quantificational elements create tripartite structures of the form $\mathrm{Q}[\mathrm{A}][\mathrm{B}]$, where $\mathrm{A}$ is the restriction of $\mathrm{Q}$ (or 1ts left argument) and $\mathrm{B}$ is the (nuclear) scope of $\mathrm{Q}$ (or its right argument) (cf. Heim 1982).

b. If- and when-clauses form the restriction of a (possibly null) adverb of quantification (see Kratzer 1986).

More specifically, in a structure of unselective binding, although the unselective bınder has inherent quantificational force (unlike the indefinites it binds), it nevertheless lacks inherent restriction, and hence depends upon the if- or when-clause to supply its restriction (see von Fintel 1994 for a discussion of the pragmatic nature of quantifier restriction). Consider now bare conditionals in Chinese. Even though there is no overt if in these clauses, the antecedent clause of a bare conditional serves as the restric-

9 A reviewer notes that if the $w h$-words are treated as generalized quantifiers (as in the cases in ruguo-conditionals), there is no need for existential closure However, it should be noted that the $w h$-words in bare conditionals are not generalized quantıfiers even after they are licensed (as polarity items). In particular, the $w h$-words are interpreted as having universal force The question of existential closure still arises, though it does not arise in cases of ruguoconditionals See also Diesing 1992.

10 The wordings in (31) are from Chierchia 1992 
tion of the necessity operator and the consequent clause as the nuclear scope of the operator. In other words, (12a) roughly has the representation in (32):

$$
\begin{array}{lll}
\mathrm{NEC}_{\mathrm{x}} & {[\mathrm{x} \text { comes first }]} & {[\mathrm{x} \text { eats first }]} \\
\mathrm{Q}_{\mathrm{x}} & \text { restriction } & \text { nuclear scope }
\end{array}
$$

Now consider again the question of why the $w h$-words must appear in pairs. Here we adopt the formulation of the prohibition against vacuous quantification from Kratzer (1989):

\section{Prohibition Against Vacuous Quantification}

(Kratzer 1989, p. 155)

For every quantifier $Q$, there must be a variable $x$ such that $Q$ binds an occurrence of $\mathrm{x}$ in both its restrictive clause and its nuclear scope.

If the $w h$-words only appear in the antecedent clause, (33) will be violated. That is, since the consequence clause is the nuclear scope of the operator, it must contain a variable for the operator to bind. Also, if the wh-word(s) only appear in the consequent clause, (33) again will be violated."

\subsubsection{Pronouns, Empty Categories, and Definite Descriptions}

Consider now the fact that the second $w h$-word in a bare conditional cannot be replaced by a pronoun, an empty category, or a definite description. In the case of a pronoun, since it is not interpreted as having independent reference, there are two possible interpretations: (i) as a bound variable or (ii) as an E-type pronoun. As a bound element, there are two possible binders: the necessity operator and the $w h$-word in the antecedent clause. If the pronoun in the consequent clause is bound by the necessity operator, the ban against vacuous quantification is satisfied, but this also amounts to saying that the pronoun is a resumptive pronoun (i.e. a pronoun directly bound by an operator). We assume, however, that Chinese is like English in that it does not have true resumptive pronouns in the sense of Chao and Sells (1983) and Sells (1984). In other words, in Chinese as in English, a pronoun cannot pick up its reference from an operator in $\mathrm{A}^{\prime}$-position. Further, we take the view of Chomsky (1976), Higginbotham (1980a,b) and much subsequent work that when a pronoun is interpreted as a bound variable, it is so interpreted in virtue of the fact that it takes a variable

\footnotetext{
1 An alternative way of looking at this is to say that the unselective binder is actually a polyadic quantifier, as proposed in Chierchia (1992). Thus, it always binds the same ntuples of variables in its restriction and in its scope.
} 
(not an operator) as its antecedent. In the terminology of Higginbotham (1985) and Montalbetti (1984), in order for a pronoun to be related referentially to an operator, it must be possible to 'link' the pronoun to a variable that the operator locally binds.

Let us then consider if a pronoun in the consequent clause of a bare conditional can take as its antecedent, or be linked to, the wh-word (qua variable) in the antecedent clause:

$$
\left.\mathrm{NEC}_{\mathrm{i}} \text { [you like who }\right] \text { [I criticize him }{ }_{\mathrm{i}} \text { ] }
$$

There are two independent reasons why this possibility is ruled out. First, being linked the pronoun is, strictly speaking, still a pronominal in the syntactic sense and not a true variable, and one can regard (34) as still a case of vacuous quantification. ${ }^{12}$ Second, even if this indirect relation between the pronoun and the operator counts for meeting the principle of non-vacuous quantification, there is reason to believe that in fact the linking itself cannot be established - because the formal variable (the wh-word) is not "accessible" to it. The literature on the phenomenon of Weak Crossover contains much research on the conditions under which a pronoun can take a variable as its antecedent. Chomsky's (1976) "Leftness Condition" (so dubbed in Higginbotham 1980a) accounts for the basic cases. Others have proposed different formulations (cf. Koopman and Sportiche (1982), Safir (1985), among others). It seems, however, that empirically the most adequate characterization is contained in the Accessibility Condition of Higginbotham (1980b). Higginbotham's point is that a pronoun can take a variable as its antecedent only if the variable is accessible to it, where accessibility is defined as in (35) (see Higginbotham (1980b) for a detailed discussion of different cases):

(35) A is accessible to B iff

a. A is an empty category strongly accessible to $B$ or

b. $A$ is"an empty category whose container $\gamma B(A)$ is accessible to $\mathrm{B}$; or

c. A is not an empty category, and for some $\mathrm{C}, \mathrm{A}$ is coindexed with $\mathrm{C}$ and $\mathrm{C}$ is accessible to $\mathrm{B}$. where strong accessibility is defined as follows:

A is strongly accessible to B iff

(i) $\mathrm{A}$ is an empty category that c-commands $\mathrm{B}$; or

\footnotetext{
12 Note that vacuous quantification is a syntactic notion. See (33) for the Prohibition Against Vacuous Quantification.
} 
(ii) A is not an empty category, and for some $\mathrm{C}$, A is coindexed with $\mathrm{C}$ and $\mathrm{C}$ is strongly accessible to $\mathrm{B}$.

Note that the Accessibility Condition, which was proposed to rule in variable binding in cases involving "inversely linked" quantification but disallow Weak Crossover, also correctly' rules out bare conditionals with an anaphoric pronoun in the consequent clause. The wh-word in the antecedent clause (the A element in Higginbotham's definition) is not accessible to the pronoun in the consequent clause, first because it does not c-command the pronoun, and secondly because none of its containers (e.g., the antecedent clause) is accessible. The antecedent clause is not accessible because it is not itself an empty category and not coindexed with any empty category. Hence a pronoun in a bare conditional cannot function as a variable to satisfy the requirement of non-vacuous quantification. (Similarly, a bare conditional with a pronoun in the antecedent and a whword in the consequent is ruled out because the pronoun cannot satisfy the requirement of restrictive quantification.)

As for treating the pronoun in bare conditionals as an E-type pronoun, it is clear from the above discussion on the necessity operator that this will lead to vacuous quantification - since the pronoun is not a variable. ${ }^{13}$ In fact, an E-type pronoun is also independently ruled out when it falls within the scope of its related operator. For example, in a sentence like 'A farmer who owns a lot of donkeys thinks he is rich' the pronoun he has only a bound-variable reading, but cannot be paraphrased as 'the farmer who owns a lot of donkeys'. ${ }^{14}$

Now consider the case where an empty category is used in place of a whword in the consequent clause. If the empty category is an empty pronominal, it will lead to the same problems that we have just mentioned. On the other hand, if the empty category is a variable (granted that a variable can be base-generated), we treat it on a par with the parasitic gap examples in (36). Consider the contrast shown between (36) and (37) (examples from Safir 1985):

\footnotetext{
13 A reviewer points out that if, as we will discuss in section 3.2.1., it is possible for the necessity operator to bind a situation variable, this may obviate the problem of vacuous quantification However, if the operator binds a situation variable in the consequent clause, it must also do so in the antecedent clause (see (33)). Hence, the possible binding of the situation variable does not help regarding vacuous quantification. That is, if the necessity operator binds a situation-wh paur ( $1 \mathrm{e}$. binds two elements at the same time), then it must bind such a pair in the consequent clause as well

14 This fact presumably follows from Binding Condition C under the E-type analysis, since definite descriptions are R-expressions in the sense of the Binding Theory.
} 
(36) a. who $o_{1}$ [did you [fire $e_{1}$ ] [without informing $e_{1}$ ]]

b. who does [[John like $\left.e_{1}\right]$ and [Mary hate $\left.\left.e_{1}\right]\right]$

(37) a.? who, [did you [fire $\mathrm{e}_{1}$ ] [without informing him $\mathrm{I}_{1}$ ]

b. * who, $_{1}$ does [[John like him 1 ] and [Mary hate $\left.e_{1}\right]$ ]

Safir (1985) proposes the constraint stated in (38) to account for the contrast.

The Parallelism Constraint on Operator Binding (PCOB)

If $\mathrm{O}$ is an operator and $\mathrm{x}$ is a variable bound by $\mathrm{O}$, then for any $y, y$ a variable of $O, x$ and $y$ are $\left[\alpha\right.$ lexical].$^{15}$

The cases in which an empty variable is in the consequent clause of a bare conditional can also be accounted for by the PCOB. That is, the necessity operator cannot bind a $w h$-word ([+lexical] $)$ and an empty variable ([-lexical] $)$ at the same time because the PCOB is violated. ${ }^{16}$

Recall that the $w h$-word in the consequent clause must be identical to the wh-word in the antecedent clause. This may follow from a strong realization of the PCOB. The [ $\alpha$ lexical] requirement ensures that the variables must be either all lexical or all empty. Another way of implementing this is to say that the variables must be all identical. If one is empty and the other is lexical, the requirement is not satisfied. If this is the case, then we can ensure that the $w h$-word in the consequent clause must be identical to the one in the antecedent clause. Note that we also need to accommodate cases in which more than one wh-word appears in the antecedent clause. The variables that an unselective/polyadic quantifier binds are not necessarily identical, as we have seen earlier. However, if we separate the variables in the restriction and the nuclear scope, then we can impose the PCOB on these cases as well. That is, each variable in the restriction must be identical to a corresponding variable in the nuclear scope. This goal

15 The term "lexical" here corresponds to "phonetic realization." Thus, wh-words are [+lexical] because they are phonetically realized, whereas empty categories are [-lexical] due to the lack of phonetic realization.

${ }_{16}$ The PCOB itself is not sufficient to account for the subject-adjunct asymmetry indicated below (also see the marginal status of (37)).

(1) *Who, did the pictures of him, please $\mathrm{t}_{1}$ ?

(11) Thich book ${ }_{1}$ did you buy $t_{1}$ without reading $t_{1}$ ?

We assume that (11) is acceptable because (under an appropriate revision of the Accessibility Condition) the real gap (the trace) is weakly accessible to a pronoun in an adjunct (but not to a pronoun in a subject) That is, (11) is not necessarily treated as a case of multiple variable binding by the operator, and therefore not subject to the PCOB. Both the PCOB and the Accessibility Condition are necessary constructs, and neither can replace the other. 
can be achieved by the following generalization, which is a revised version of the PCOB:

\section{Revised $P C O B$}

In a tripartite structure of quantification $Q[A][B],\left[X_{1}, X_{2}\right.$, $\left.\ldots, X_{n}\right]$ (where $\left.n \geq 1\right)$ are variables in $A$. For every variable in $\mathrm{A}$, there must be an identical variable in $\mathrm{B}$.

Lastly, we have also seen that definite descriptions cannot be used in place of the $w h$-word in the consequent clause. If definite descriptions are directly bound by the necessity operator, they are variables. However, though definite descriptions may be used as variables, they cannot be used as such to satisfy (39) since they are not identical to the $w h$-variables in the antecedent clause. ${ }^{17}$ On the other hand, if the definite descriptions in the consequent clause are not directly bound by the necessity operator, we again have the problem of vacuous quantification (i.e. violation of (33)).

We have now seen that the properties of bare conditionals can be naturally explained once these constructions are taken as cases of unselective binding in action. Even on an intuitive level, these properties are quite natural properties of the construction. The two variables required by restrictive, non-vacuous quantification are both directly, locally bound by their operator. Hence they are of equal status as true formal variables, neither dependent on the other. Since there is no direct anaphoric relationship between them, anaphoric expressions like pronouns and definite descriptions are inappropriate.

\subsection{Dou/Ruguo-Conditionals}

Recall that dou/ruguo-conditionals present an opposite situation from the one we see in bare conditionals. There cannot be a $w h$-word in the consequent clause. Instead, a pronoun, an empty category, or a definite description is used. Furthermore, the consequent clause need not contain any anaphoric element at all. In the analysis presented above, we appeal to an implicit operator for the universal force that the $w h$-words have. We will argue in this section that the $w h$-word in the antecedent clause in doulruguoconditionals is not bound by an operator external to the antecedent clause.

17 Note that it is possible to have a definite description in the antecedent clause and an identical one in the consequent clause, as shown in (i) below:

(i)

$$
\begin{aligned}
& \text { ni xihuang nei-ge ren, wo jiu da nei-ge ren } \\
& \text { you like that-CL person I then hit that-CL person } \\
& \text { 'If you like that person, I'll then hit him/her.' }
\end{aligned}
$$


Instead, it is treated as an existential quantifier that has scope internal to the antecedent clause. Thus, there is no requirement which forces the presence of a $w h$-word in the second clause. Further, the pronoun in the consequent clause is treated as an E-type pronoun.

\subsubsection{Ruguo-Conditionals}

The first question we must address in ruguo-conditionals is related to the quantificational force of the $w h$-word as well as its licenser. We have stated that in bare conditionals, the wh-words are licensed and bound by the necessity operator and have universal force. Ruguo-conditionals differ from bare conditionals in that there is a leading element ruguo 'if' in the antecedent clause. We suggest that this leading element is the licenser of the $w h$-word(s) in the antecedent clause. Just as in the case of polarity any, the leading element 'if' licenses a $w h$-word in its scope as a (generalized) existential quantifier. Once licensed, the $w h$-word is treated as an existential quantifier in the traditional sense, subject to Quantifier Raising, which adjoins it to the antecedent clause IP. The QR-ed existential quantifier is then analyzed in terms of a restrictive quantification schema, with its determiner (overt or covert) mapped onto an operator position, and its $\mathrm{N}^{\prime}$ mapped onto a restrictive clause. The operator binds a variable in the restrictive clause mapped from $\mathrm{N}^{\prime}$, and another variable - the trace left by $\mathrm{QR}$ - in the nuclear scope, in this case the antecedent clause. Thus, a ruguo-conditional such as (40a) has an LF representation like (40b), which is mapped to the semantic representation in $(40 \mathrm{c}):^{18}$

$$
\begin{aligned}
& \text { (40) a. ruguo ni kan-jian le shei, jiu jiao ta la la } \\
& \text { if you see ASP who then tell him/her come } \\
& \text { jian wo } \\
& \text { see me } \\
& \text { b. ruguo [shei } i_{\mathrm{i}} \text { [ni kan-jian le } \mathrm{t}_{\mathrm{j}} \text { ], [jiu jiao ta lai jian wo] } \\
& \text { c. If (for some } \mathrm{x} \text {, ( } \mathrm{x} \text { a person) (you see } \mathrm{x} \text { )), then tell him/her to } \\
& \text { come see me. }
\end{aligned}
$$

Note that the representation (40c) satisfies the prohibition against vacuous

\footnotetext{
18 As an alternative, rather than treating the $w h$-word as a quantifier, we might still treat it as a variable "caught" by existential closure (Heim 1982, Diesing 1992) in the absence of a binder ('if' being merely a licenser). The existential closure has scope internal to the if-clause. If we follow Heim and Diesing and assume that in such cases no restrictive clause is needed, the relevant facts are also accounted for. We shall not pursue this option, so as to preserve a unified assumption of a tripartite structure for quantificational sentences.
} 
quantification (33). The relevant tripartite structure is already 'complete' within the antecedent clause. There is then no need for an additional $w h$ word in the consequent clause. Instead, an anaphoric element like a pronoun or definite description can, but need not, appear in that clause. That the $w h$-word(s) in a ruguo-conditional have existential force is evidenced by the following fact.

In Mandarin Chinese, indefinite subject NPs can be preceded by the existential verb/marker you 'have, there is', as shown in (41a-b), while definite subject NPs cannot, as in (41c). ${ }^{19}$ The sentences in (42) and (43) show a clear contrast between bare conditionals and ruguo-conditionals. The former does not allow you 'have' to precede a $w$ h-subject while the latter does, indicating that the $w h$-word in ruguo-conditionals has existential force. ${ }^{20}$
(41) a. (you) yi-ge-ren lai le
have one-CL-person come ASP
'One person came.'

b. (you) shei lai le

have who come ASP

'Who came?'

c.* you nei-ge-ren lai le

have that-CL-person come ASP

'That person came.'

(42)

*you shei xian lai, shei xian chi
have who first come who first eat
'If $X$ comes first, $X$ eats first.'

19 In some cases, such as the sentence in (i), the presence of you 'have' is obligatory.

(i) *(you) ren lai-le

have person come-ASP

'Someone came.'

20 Note that you 'have' only functions as an indefinite marker/indicator when it precedes the subject. In presentational sentences or sentences involving possession, you 'have' does not mark an indefinite NP (see for instance (i) below). See Huang 1987 for a discussion of indefiniteness/definiteness effects in Chinese. (i) jintian you shenme, chi shenme
today have what eat what

'Whatever (we) have today, (we) eat today.' 
(43)

$$
\begin{aligned}
& \text { ruguo you shei qiao men, ni jiu jiao ta } \\
& \text { if have who knock door you then ask him/her } \\
& \text { jin-lai } \\
& \text { come in } \\
& \text { 'If someone knocks on the door, you'll ask him/her to come } \\
& \text { in.' }
\end{aligned}
$$

We have seen that, given our analysis of the wh-word as an existential quantifier that takes scope over the antecedent clause, a complete tripartite structure can be obtained within the antecedent clause. This explains why there is no need for a second $w h$-word in the consequent clause. In fact, this also helps to explain why a $w h$-word cannot appear in the consequent clause at all. Since the $w h$-word in the antecedent clause is already licensed as an existential quantifier in the antecedent clause, if there is another whword in the consequent clause, that wh-word would need to have a licenser and a binder also. The only likely licenser and binder in such a case is the necessity operator. However, the presence of the necessity operator will lead to the problems we have just noted in section 3.1. That is, the tripartite structure formed in such a case will not have a variable in the restriction. ${ }^{2 !}$

The necessity operator, however, can be present. It does not bind the $w h$-word(s) in the antecedent clause since they are already bound and licensed. Instead, the necessity operator can range over cases or situations (see Berman 1987 and Heim 1990). Thus, a sentence such as (23b), repeated below, has the interpretation in (44).

(23b) ruguo ni kandao shei, qing jiao ta lai jian if you see who please tell him/her come see

wo

me

'If you see someone, please ask him/her to come see me.'

(44) For every situation (s), if you see someone in (s), please ask him/her to come see me in (s).

21 Note that we have stated that ruguo 'If' licenses the wh-word(s) in the antecedent clause as an existential quantifier. This does not entail that ruguo is the element that provides existential force to the $w h$-phrase One way of looking at this is to adopt Diesing's proposal of indefinites in English. That is, wh-words in Mandarin are similar to indefinites in English in that they have both variable status and true existential quantifier status. The difference we see in Chinese is that the $w h$-words must have a licenser The variable status of $w h$ words allows them to be bound by the necessity operator, while the true existentral quantifier status allows them to have existential force in ruguo-conditionals 
Since the necessity operator binds a situation variable, it does not require another $w h$-word to be present in the consequent clause (i.e. the prohibition against vacuous quantification is satisfied).

One may ask why the necessity operator does not range over situations in bare conditionals. We think that in fact it does (see also footnote 13). Recall that the necessity operator is an unselective/polyadic quantifier. It can bind many variables at the same time. Thus, in a bare conditional such as (12), the necessity operator can also range over situations. The reading will be roughly as in (45).

$$
\begin{aligned}
& \text { shei xian lai, shei xian chi } \\
& \text { who first come, who first eat } \\
& \text { 'If X comes first, X eats first.' }
\end{aligned}
$$

(45) For all ( $\mathrm{x}, \mathrm{s}$ (ituation)) (if $\mathrm{x}$ comes first in $\mathrm{s}$ ), ( $\mathrm{x}$ eats first in $\mathrm{s}$ ).

In other words, the necessity operator in (12) binds a pair of variables, one of which is a situation variable.

3.2.1.1. E-type Pronouns. We have explained why donkey anaphora in ruguo-conditionals cannot take the form of a wh-word. From the same analysis it clearly also follows that the consequent clause need not contain any anaphoric element at all. However, our analysis allows anaphoric elements such as a pronoun, an empty category, or a definite description in the consequent clause. We propose that the pronoun in the consequent clause which refers to the wh-word is an E-type pronoun. In other words, a ruguo-conditional such as (23b) (repeated below) will have the interpretation indicated in (46).

$\begin{array}{llllllll}\text { ruguo } & \text { ni kandao } & \text { shei, qing jiao ta lai jian } \\ \text { if } & \text { you see } & \text { who please tell him/her come see } \\ \text { wo } & & & & & & & \\ \text { me } & & & & & & & \end{array}$

'If you see someone, please ask him/her to come see me.'

(46) If you see someone, please ask the one you see to come see me.

As mentioned earlier, Evans (1980) shows that an E-type pronoun cannot refer to NPs such as no girls, no one, no sheep etc., in contrast to a true bound pronoun (examples from (4) are repeated below as (47)).

(47) a. No congressmen admire only the people they know.

b. No congressmen admire Kennedy, and they are very junior. 
Examples of ruguo-conditionals show that the antecedent clause cannot have an expression equivalent to no one as the antecedent of the pronoun ta.

$$
\begin{aligned}
& \text { *ruguo meiyou shei ma ni, ni jiu jiao ta } \\
& \text { if not-have who scold you, you then ask him/her } \\
& \text { lai jian wo. } \\
& \text { come see me } \\
& \text { *If no one scolds you, then you ask him/her to come see me.' }
\end{aligned}
$$

This fact is consistent with the supposition that the pronoun in a ruguoconditional is an E-type pronoun. ${ }^{22}$

In ruguo- as well as dou-conditionals, the pronoun can be replaced by an empty element or a definite description. The fact that it can be a definite description is not a surprise since that is exactly what the interpretation of an E-type pronoun is. As for empty elements, the pronoun can be replaced by an empty pronoun, though not as a variable. An empty pronoun will be just an empty version of an E-type pronoun. The empty element cannot be a variable, since a variable needs to be bound. Even though the necessity operator can bind it, the binding will not create the right tripartite structure since there is no comparable variable in the restriction.

Note again that given our analysis, the unselective/polyadic binding cases are the ones in which the $w h$-words are independently bound by the necessity operator. Each $w h$-word has an independent status as a variable, and none is anaphoric to another. In contrast, in the ruguo cases the elements in the consequent clause are dependent on the wh-words in the antecedent clause. Hence such elements must be anaphoric in form.

\subsubsection{Dou-Conditionals}

Dou-conditionals are similar to ruguo-conditionals in that the consequent clause may contain a pronoun, an empty element, or a definite description, but cannot contain another wh-word. However, the interpretation of dou-conditionals differs from that of ruguo-conditionals. In particular, dou-conditionals resemble the "unconditionals" that Zaefferer (1990) discusses. Zaefferer states that unconditionals strengthen a claim by stating "that it holds independent of the choice from some alternatively conceiv-

\footnotetext{
22 The ungrammaticality of (48) may also be related to the licensing and binding of the $w h$-word shel in the expression melyou shel, which is equivalent to 'no one'.
} 
able circumstances." We will discuss the formal properties of dou-conditionals further below.

In dou-conditionals, the pronoun also cannot have a negative quantificational expression as an antecedent, which is consistent with an E-type pronoun analysis:

$$
\begin{aligned}
& \text { * meiyou shei qiao men, ni dou jiao ta jinlai } \\
& \text { no-have who knock door you all ask him/her enter } \\
& \text { * 'If no one knocks on the door, you will then ask him/her to come } \\
& \text { in.' }
\end{aligned}
$$

Given the data we have seen, the $w h$-word in the antecedent clause of a douconditional appears to be a quantifier. Is it a universal or an existential quantifier? The sentence below suggests that she $i$ in the antecedent clause is existential, given the fact that the pronoun that follows it can take the singular form, paraphrasable as 'the person you ask to come in':

(22b) ni jiao shei jin-lai, wo dou jian ta you ask who come in I all see him/her

'Whoever you ask to come in, I will see him/her (the person who you ask to come in).'

The truth condition of $(22 \mathrm{~b})$ is roughly (50):

(50) For all $\mathrm{x}, \mathrm{x}$ (a person you ask to come in), I will see $\mathrm{x}$.

As mentioned earlier, an E-type pronoun taking a universal quantifier as its antecedent must be plural in form. We shall then treat dou-conditionals on a par with ruguo-conditionals as involving existential quantification internal to the antecedent clause, from which it follows that these two constructions share the same clustering of properties under consideration, in contrast to bare conditionals.

There is an important question, however, that stands in the way of treating dou-conditionals in terms of existential quantification. As the truth condition of (50) is intended to show, the sentence has the force of universal quantification. It is true just in case on every assignment of the value of $\mathrm{x}$ such that you ask $\mathrm{x}$ to come in, I will see $\mathrm{x}$; and it is false otherwise. To ascertain the correctness of our assumption, we must first consider the role of dou more closely and resolve what now appears to be a contradiction.

3.2.2.1. The Role of Dou 'All'. The idea that the dou-conditionals involve existential quantification is somewhat surprising given the well-known 
fact that dou triggers universal quantification over the denotation of an expression to its left: ${ }^{23}$

(51) a. dajia dou hen xihuan ta.
everyone all very like him/her
'Everybody likes him/her.'
b. ta shenme dou chi.
s/he what all eat
'S/he eats everything.'

Dou-conditionals have apparent differences from ruguo-conditionals. The former do not have a leading element in the antecedent clause while the latter do not have the quantifier dou 'all' in the consequent clause. While it is commonplace knowledge that a polarity item in the scope of if has the status of an existential quantifier, it has also been commonly assumed in the literature that a $w h$-word to the left of dou (as in (51b)) is used as a universal quantifier.

We shall now argue that this latter assumption is incorrect, at least for the cases of dou-conditionals under consideration. More specifically, we claim that the antecedent clause of a dou-conditional is an elliptical phrase containing an embedded question. As an embedded question, the 'antecedent clause' is then interpreted as having the force of existential quantification, given the standard semantics of questions. The donkey pronoun or definite description refers to the $w h$-word qua existential quantifier. The similarities between ruguo- and dou-conditionals then follow straightforwardly. As for the adverb dou, which triggers universal quantification, we argue that it quantifies over the set of propositions that is the denotation of the question (see Hamblin 1973; cf. Harttunen 1977, Engdahl 1986, Lahiri 1991, among others). There is then no contradiction in saying that dou-conditionals involve both existential and universal quantification.

23 There are some apparent exceptions to this long-held observation, represented by examples like (1).

(1)

$$
\begin{aligned}
& \text { nı dou mai-le shenme' } \\
& \text { you all buy-ASP what } \\
& \text { 'What did you buy', }
\end{aligned}
$$

Such exceptions occur only with $w h$-questions, and only with those with the presupposition that the wh-word ranges over a non-singleton set. We believe that such cases can be naturally accounted for by the assumption that quantification is over minimal events, or situations, that are 'slices' of a larger event/situation involving multiple objects. For more discussion on this issue see Cheng 1995 and Li 1994; for more general discussion on the syntax of dou see Cheng 1991, 1995, and references cited there. 
As support for the proposal that dou-conditionals involve elliptical embedded questions, note that the antecedent clause can in fact be fully spelled out with the question embedded under the subordinating conjunction bulun 'regardless of', which we assume s-selects an interrogative proposition as its complement. (We shall assume that bulun 'regardless of' has a categorial status on a par with ruguo 'if', a $\mathrm{P}$ or a $\mathrm{C}$, which sselects a non-interrogative.)

$$
\begin{aligned}
& \text { bulun ni jiao shei jin-lai, wo dou jian ta } \\
& \text { regardless you ask who come-in I all see him/her } \\
& \text { 'Regardless of who you ask to come in, I will likewise see } \\
& \text { him/her.' }
\end{aligned}
$$

Further support for the interrogative status of the antecedent clause comes from the fact the clause may contain the wh-elements that have only an interrogative use. For example, we have seen that a $w h$-word like shei 'who' or shenme 'what' can have the use of a non-interrogative phrase, either as a variable with universal force under unselective binding or as an existential quantifier in polarity contexts. However, interrogative forms like weishenme 'why' or the 'A-not-A' construction are excluded from such uses. Neither can be used in bare conditionals or ruguo-conditionals:
a.* ta lai-bu-lai, wo jiu lai-bu-lai
he/she come-not-come I then come-not-come
b.*ta weishenme bu lai, wo jiu weishenme bu qu he/she why not come I then why not go

$$
\begin{aligned}
& \text { a.* ruguo ta lai-bu-lai, wo jiu rang ta gen } \\
& \text { if he/she come-not-come I then let him with } \\
& \text { ni shuo hua. } \\
& \text { you say word } \\
& \text { b.* ruguo ta weishenme lai, wo jiu rang ta } \\
& \text { if he/she why come I then let him/her } \\
& \text { gen ni shuo hua. } \\
& \text { with you say word }
\end{aligned}
$$

(53a) cannot be accepted as making the assertion that I will follow him whichever choice he makes between 'come' and 'not come', i.e., I will come if he comes, and I will not come if he does not. Similarly, (53b) is not acceptable as making the assertion that whatever his reason will be for not coming, it will be the reason for my not going. In (54), the condi- 
tional clause is unacceptable with the intended meaning "if he makes one choice or another between 'come' and 'not come'," or "if he comes with (at least) one reason" (then, I will let him speak with you). ${ }^{24}$

In contrast with these sentences, corresponding dou-conditionals are perfectly well-formed:

(55) a. ta jintian lai-bu-lai, wo dou bu deng
he/she today come-not-come I all not wait
'Whether he/she comes or not today, I won't wait for
b. ta weishenme mei lai, wo dou bu hui
he/she why not come I all not will
yuanliang ta.
forgive him/her

'Regardless of why he didn't show up, I won't forgive him/her.'

The well-formedness of (55) shows that the antecedent clause of a douconditional is an embedded question. It should be noted, then, that what we have called a dou-conditional is really not a conditional in the typical sense (though we shall continue to call it a conditional). This is further evidenced by the fact that the 'antecedent clause' cannot take ruguo, and the 'consequent clause' cannot take jiu 'then' (in addition to dou), unlike the bare and ruguo-conditionals:

(56) a.* ruguo ni kanjian-le shei, wo dou jian ta. if you see who I all see him/her $\begin{array}{cll}\text { b.*ni kanjian-le shei, wo jiu dou jian ta. } \\ \text { you see } & \text { who I then all see him/her }\end{array}$

A natural question that arises at this point is why the antecedent clause must be a question. The answer is that this is forced by the presence of dou 'all', which requires something to its left to be universally quantifiable, hence something that can be construed as denoting a plural set of entities such as a question. The semantics of 'regardless of' allows the set of propositions (or circumstances) that satisfy the embedded question to be universally quantified, but a pure conditional clause, which cannot occur in construction with 'regardless of', does not. Hence a non-inter-

\footnotetext{
24 Incidentally, note a similar gap in English regarding the affixation of -ever and some-: *whyever, *whetherever, *somewhy, ${ }^{*}$ somewhether. For some discussion of the internal structure of $w h$-words in Chinese and English, see Cheng 1991 and Tsai 1994.
} 
rogative sense of the $w h$-word in the antecedent clause is not possible. In addition, as mentioned earlier, dou-conditionals appear to resemble a certain type of conditionals called "unconditionals" by Zaefferer (1990). Zaefferer notes that "unconditionals seem to be encoded in most languages by interrogative clauses, more precisely by alternative and constituent interrogatives" (p. 489). The reason why languages tend to use interrogatives in unconditionals, according to Zaefferer, is that interrogatives "define sets of issues ... as representing exhaustively the range of options that are currently taken into considerations," and that it is the exhaustiveness that lead to the unconditional interpretations.

Recapitulating, then, in a dou-conditional there is universal quantification ranging over the set of propositions that define the embedded question in the antecedent clause. At the same time, since interrogative $w h$-words have the status of an existential quantifier having scope internal to the embedded question, an interrogative phrase in such a construction will undergo $w h$-movement into the Spec of the embedded clause and have scope over it (as in the tradition of Huang 1982). Thus the consequent clause may contain an overt or covert E-type pronoun or a definite description (or it may contain no such element at all), but it crucially cannot contain another $w h$-word. This range of properties falls out in the same way as those observed with ruguo-conditionals.

\subsection{Apparent Alternations}

In section 2 we saw data from Yu (1965) which indicate possible alternations between a $w h$-word and a pronoun in bare conditionals. The examples are repeated below as (57):

(57) a. shei yao zhe puo-chang, wo jiu rang gei who want this broken-factory I then give to

talshei

him(her)/who

'Whoever wants this broken factory, I'll give it to him/her.'

b. shei bu dui, wo jiu shuo ta/shei bu dui who not right I then say he(she)/who not right

'Whoever is not right, I'll say that he/she is not right.'

In these two examples, donkey anaphora can be expressed with either a $w h$-word or a pronoun. As they stand, these examples are problematic to the analysis presented above. In contrast to these data, we have found that 
there is otherwise a general complementary relationship between $w h$-words and pronouns in the consequent clause.

We will argue here that the apparent alternation is due to the possibility of omitting ruguo 'if' in ruguo-conditionals. First, we have observed above that these unexpected alternations are found only where the second clause contains the element jiu 'then'. With a "completely bare" conditional (with neither ruguo nor jiu), no alternation is allowed ((21) is repeated below):

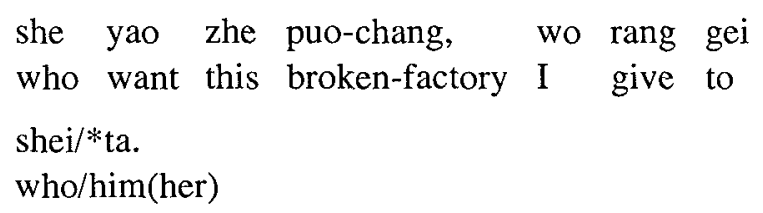

'Whoever wants this broken factory, I will give it to him/her.'

This shows that in a typical bare conditional, alternations are not allowed, as our analysis predicted. Note, however, that as we have seen in section 2.1 , it is possible to have jiu 'then' in a bare conditional and, thus, examples such as (57) can also be bare conditionals. Consider now typical ruguoconditionals such as (58).

(58) a. ruguo hufei lai, wo jiu liu-xia-lai if Hufei come I then stay

'If Hufei comes, then I will stay.'

b. hufei lai, wo jiu liu-xia-lai

Hufei comes, I then stay

'If Hufei comes, then I will stay.'

In (58b), we see that the leading element ruguo 'if' in a ruguo-conditional can be optional. We will call such a conditional a "reduced" ruguo-conditional. There is no meaning difference between (58a) and (58b). Crucially, (58b) is interpreted as a conditional. Hence, based on (58b) and the possibility of having jiu 'if' in a bare conditional, sentences such as (58) can be ambiguous between a "reduced" ruguo-conditional and a bare conditional. In other words, in these examples, when the donkey pronoun is in a $w h$-form, we are dealing with a bare conditional, and when it is an anaphoric pronoun, we are dealing with a "reduced" ruguo-conditional.

Furthermore, in examples such as (57), when an anaphoric pronoun is used, it has to be in the singular form, as in (59), showing that we are dealing with a $w h$-word with existential force in the antecedent clause. 
(59) a. shei yao zhe puo-chang, wo jiu rang gei

who want this broken-factory I then give to

ta/*tamen

him(her)/them

'Whoever wants this broken factory, I'll give it to him/her.'

b. shei bu dui, wo jiu shuo ta/*tamen bu dui who not right I then say he(she)/them not right

'Whoever is not right, I'll say that he/she is not right.'

$(59 \mathrm{a}, \mathrm{b})$ further confirm our analysis that (57) is a "reduced" ruguo-conditional; the $w h$-word does not have universal force. In short, there is in fact no "alternation." The examples in (57) are simply realizations of an ambiguity between bare conditionals with jiu 'then' and "reduced" ruguoconditionals.

\subsection{Mixed Cases}

The data we have presented so far involve sentences that use either the unselective binding strategy or the E-type pronoun strategy. As sentences (60)-(61) show, a mixed strategy may also be used:

(60) shei yan shei ta jiu de xiang shei who play who s/he then must resemble who 'If X plays the role of $\mathrm{Y}$, then s/he must resemble $\mathrm{Y}$.'

(61) shei xiang chi shenme, ta jiu chi shenme who want eat what $s /$ he then eat what

'If $\mathrm{X}$ wants to eat $\mathrm{Y}, \mathrm{s} / \mathrm{he}$ then eats $\mathrm{Y}$.'

In both (60) and (61), the subject of the consequent clause is an overt pronoun. However, the objects in the antecedent clause and the consequent clause are $w h$-words. We consider these to be mixed cases, which use both the unselective binding strategy (object) and the E-type strategy (subject). The latter strategy is possible because the sentences may be analyzed as ruguo-conditionals with jiu 'then'. As noted earlier, when jiu 'then' is absent, the conditionals are 'completely bare'. In these mixed cases, jiu 'then' cannot be absent:

(62) * shei yan shei ta de xiang shei who play who s/he must resemble who 'If $\mathrm{X}$ plays the role of $\mathrm{Y}, \mathrm{s} / \mathrm{he}$ must resemble $\mathrm{Y}$.' 
(63)

$$
\begin{aligned}
& \text { *shei xiang chi shenme, ta chi shenme } \\
& \text { who want eat what s/he eat what } \\
& \text { 'If } \mathrm{X} \text { wants to eat } \mathrm{Y}, \mathrm{s} / \mathrm{he} \text { eats } \mathrm{Y} \text { '. }
\end{aligned}
$$

In these grammatical mixed cases, the non-overt ruguo 'if' can pick one or more NPs to license. In the examples we have seen, ruguo 'if' only picks one NP (the subject) to license and thus the subject in the antecedent clause is existential.

The option of licensing only the subject as existential leaves the object $w h$-word unlicensed. In this case the necessity operator comes in as an unselective binder and licenser, giving it universal force. Thus, the object wh-words in these mixed cases have universal force. As shown in these examples, the related NP used in the consequent clause can be an anaphoric pronoun if it corresponds to an existential $w h$-word. In contrast, since the object $w h$-word in the antecedent clause is licensed and bound by the necessity operator, the related NP in the consequent clause can only be in the form of a wh-word. ${ }^{25}$

We have proposed that in these mixed cases, there is a non-overt ruguo 'if'. It should be noted that if ruguo is overt, mixed cases are not allowed, as shown in (64).

$$
\begin{aligned}
& \text { *ruguo shei yan shei ta de xiang shei } \\
& \text { if who play who s/he must resemble who } \\
& \text { 'If X plays the role of } \mathrm{Y}, \mathrm{s} / \text { he must resemble } \mathrm{Y} \text {.' }
\end{aligned}
$$

Thus, it appears that the presence of overt ruguo 'if' blocks the licensing and binding of the $w h$-words from the necessity operator. Given a sentence such as (64), even though ruguo can license the subject and the object $w h$-words in the antecedent clause, the object $w h$-word in the consequent clause cannot be licensed.

25 Jo-wang Lin (pers. comm.) points out that (i) is not as good as the other mixed cases shown here.

(i)

$$
\begin{aligned}
& \text { *shei yan shei, shei jiu de xiang ta } \\
& \text { who play who who then must resemble s/he } \\
& \text { 'If X plays the role } Y \text {, then } X \text { must resemble him/her.' }
\end{aligned}
$$

(i) shows that there is a subject-object asymmetry in mixed cases. The sentence differs from the other grammatical mixed cases in that the NP that is being licensed by the non-overt ruguo 'if' is the object rather than the subject. We tentatively surmise that this is a locality/ minimality effect on licensing. If licensing is done from top to bottom and cannot skip, then we would not expect the object to be licensed but not the subject. 


\section{4. $\forall$ AND $\exists$ READINGS}

As Chierchia (1992) and others point out, the indefinite NP in donkey sentences may have what he calls ' $\forall$ and/or $\exists$ readings'. For instance, in (65), the indefinite a dime only has a $\exists$ reading. In contrast, (66) seems to have the $\forall$ reading only.

(65) Every (most, etc.) person who has a dime will put it in the meter.

(Pelletier and Schubert 1989)

(66) Every man who owned a slave owned his/her offspring.

In (65), a $\forall$ reading would mean that every man will put every dime he has into the meter. But this reading is in fact the least likely reading we get. An unselective binding analysis which treats (65) as universal quantification over person-dime pairs fails to exclude this reading. On the other hand, the classic donkey sentence can have either the $\forall$ or the $\exists$ reading, depending on the context (see Chierchia 1992 for details).

In the two types of donkey sentences discussed in this paper, we can see a contrast in terms of $\forall$ and $\exists$ readings. In particular, the bare conditionals only have the $\forall$ reading, while the ruguo-conditionals can have either the $\exists$ reading or the $\forall$ reading. Further, in dou-conditionals, due to the presence of $d o u$ 'all', we have a situation in which the wh-word is existentially quantified but the sentence also exhibits a $\forall$ reading.

\subsection{Bare Conditionals}

In our analysis of bare conditionals, the wh-words are each locally bound by a necessity operator which provides universal force. According to this analysis, all the $w h$-words in a bare conditional are interpreted universally. Consider now the sentence in (67):

(67) ni xihuan shei, wo jiu xihuan shei
you like who I then like who 'If you like X, I will then like X.'

The truth condition of (67) is roughly:

(68) For all $\mathrm{x}, \mathrm{x}$ a person you like, I will like $\mathrm{X}$.

The truth condition of (67) requires that I like all the people that you like. In particular, the sentence is false if you like four people but I only like three of them. 


\subsection{Dou/Ruguo-Conditionals}

We have shown earlier that the wh-words in ruguo and dou-conditionals have existential rather than universal force. However, we have also shown that in dou-conditions, dou 'all' contributes universal quantification over the embedded question in the antecedent clause. The contrast between (69) and (70) shows that ruguo-conditionals differ from dou-conditionals in that the latter yield a $\forall$ reading.

(69) ni you shenme pengyou, wo dou hui ba ta you have what friend I all will $\mathrm{BA}$ him/her jieshao gei Lisi introduce to Lisi

'If you have a friend, I will always introduce him/her to Lisi.'

(70) ruguo ni you shenme pengyou, jiu jieshao if you have what friend then introduce ta gei Lisi him/her to Lisi

'If you have a friend, you should introduce him/her to Lisi.'

The truth condition of (69) is given in (71):

(71) $\quad \forall_{\mathrm{p}}\left(\left(\exists_{\mathrm{x}}(\mathrm{x}\right.\right.$ a friend $)[\mathrm{p}=\wedge$ you have $\left.\mathrm{x}]\right) \rightarrow$ I will introduce him/her (the friend that you have) to Lisi in the event of $p$ )

In this representation, the elliptical embedded question '[regardless of] what friend you have' is interpreted by an existential quantification over friends representing a set of propositions that constitute the denotation of the question. Then the presence of dou and the semantics of the implicit 'regardless of' trigger universal quantification over members of this set. The truth condition of (71) entails ' $\forall_{\mathrm{x}}((\mathrm{x}$ a friend that you have $) \rightarrow$ (I will introduce $x$ to Lisi))'. The logical representation of (71) correctly captures the fact that (69) will be false if only some of your friends are introduced to Lisi.

In contrast, the truth condition of (70) does not require that all friends of yours be introduced to Lisi. As long as one of them is introduced, the sentence will be true. The logical representation of (70) is (72).

(72) For some $\mathrm{x}, \mathrm{x}$ a friend of yours, I will introduce $\mathrm{x}$ to Lisi.

Note that it is also possible to have a $\forall$ reading in this case. In such a 
case, every friend of yours must be introduced to Lisi. The choice between the $\forall$ reading and the $\exists$ reading appears to depend on context.

In dou-conditionals, the $\forall$ reading is required even though the whwords are existentially quantified. And in ruguo-conditionals, even though we can have the $\exists$ reading, it is also possible to get the $\forall$ reading. Obviously, the $\forall$ reading is not contributed by the quantificational force that the $w h$ words have, but by other factors. In the case of dou-conditionals, we have shown that it is contributed by dou 'all' (and the semantics of an implicit 'regardless of'). In the case of ruguo-conditionals, we suggest that the $\forall$ reading comes from the possible presence of the necessity operator ranging over minimal situations. If every (minimal) situation is considered, then in every situation in which a friend of yours is involved, that friend of yours will be introduced to Lisi. This is the $\forall$ reading. Since the $\forall$ reading is contributed by an implicit operator, we predict quantificational variability in the presence of other overt adverbs of quantification. This prediction is borne out. Thus to a sentence like (73) one may add an adverb such as tongchang 'usually', youshi 'sometimes', or henshao 'seldom', and the sentence may be interpreted as if it had the quantificational force of a most-, some-, or $f e w-N^{\prime}$, respectively (the reader can verify this point for himself/herself):

$$
\begin{array}{lllll}
\text { ruguo wo you shenme shi, hui tongzhi ni. } \\
\text { if I have what thing will inform you }
\end{array}
$$

'If I have something (in my mind), I will let you know.'

This shows, incidentally, that quantificational variability under adverbs of quantification does not, by itself, entail unselective binding of an indefinite. The variability can be observed equally well when the adverbs simply quantify over situations (see also footnote 2). In Chierchia (1992), it suggested that the $\forall$ reading comes from the E-type pronoun strategy. We have seen that the unselective/polyadic binding strategy also has the $\forall$ reading. In fact, it is this type of strategy which has consistent $\forall$ readings. In contrast, in the E-type pronoun strategy cases, both $\forall$ readings and $\exists$ readings are possible. Hence, it appears that the E-type pronoun strategy does not entail $\forall$ readings only and $\forall$ readings are not particular to the E-type pronoun strategy.

\section{The Proportion Problem}

Another controversial area in donkey anaphora has to do with the "proportion problem' and the distribution of symmetric and asymmetric readings. 
The problem has to do with whether an adverb of quantification is anchored to one or all of the indefinites in a given sentence:

(74) If a farmer owns a donkey, he is usually rich.

Consider a scenario with 100 farmers, 99 of whom each own one donkey and are poor and the 100th of whom owns 200 donkeys and is rich. Following the terminology of Kadmon, the symmetric reading is the one according to which the adverb is anchored to both a farmer and a donkey, i.e., to minimal situations where exactly one farmer owns exactly one donkey. Thus according to this reading, the sentence is purported to assert that in most cases involving a minimal farmer-donkey pair, the farmer is rich. For the scenario under consideration, the sentence is purported to be true because it asserts that of the 299 farmer-donkey pairs, most (200) pairs involve a rich farmer. The subject-asymmetric reading is the one in which the adverb is anchored to a farmer, to situations that are minimal with respect to the farmers (exactly one farmer who owns one or more donkeys). In the current scenario the sentence is purported to be false because it asserts that of the 100 farmer-donkey pairs, more than half involve a poor farmer. In an object-asymmetric reading, the adverb would be anchored to situations that are minimal with respect to the donkeys only (exactly one donkey which is owned by one or more farmers). The fact is that for a sentence like (74), the subject-asymmetric reading is (almost) the only reading available (as speakers have no problem judging the sentence to be false under the current scenario). The problem is whether this fact can be predicted by a proper theory of indefinites, such as unselective binding or the E-type strategy.

We agree with Heim (1990) and Chierchia (1992) in believing that the proportion problem does not directly rest on the choice between unselective binding and the E-type analysis. As Chierchia (1992) shows, all three readings considered above may in principle be available for a sentence like (74), the relative salience of a particular reading being determined by pragmatic factors such as topic choice. (In the default cases, the subjectasymmetric reading is salient, presumably because subjects are more topical.) We show briefly here that both types of donkey sentences in Chinese can have symmetric as well as asymmetric readings. This confirms the view that the proportion problem does not distinguish between the two strategies of analyzing donkey sentences, and that both of them are needed in natural language. We do not commit ourselves as to how to account for the asymmetric readings; for it is likely that this question is not to be answered within the core domain of grammar (see Heim 1990 and Chierchia 1992 for detailed discussions). 
Consider the following examples:

Bare Conditional

shei yan shei, shei tongchang jiu xiang shei who play who who usually then resemble who 'If X plays the role of $\mathrm{Y}$, then usually $\mathrm{X}$ will resemble $\mathrm{Y}$.'

(76) Dou-Conditional

shei yan shei, ta tongchang dou hui xiang who play who s/he usually all will resemble nei-ge-jiaose that-CL-role

'If $\mathrm{x}$ plays the role of $\mathrm{Y}$, then $\mathrm{X}$ usually will be similar to the role of Y.'

(77) Ruguo-Conditional

ruguo shei yan shei, ta tongchang jiu hui if who play who $\mathrm{s} / \mathrm{he}$ usually then will xiang nei-ge-jiaose

resemble that-CL-role

'If $X$ plays the role of $Y$, then $X$ usually will be similar to the role of Y.'

In all of these cases, if there is a topic specified, the sentence becomes asymmetric with respect to the topic. Take (75) for instance. If the speaker first says "with respect to the characters (roles) in this play," then the reading will be asymmetric with respect to the roles. Thus, the example shows that topic choice is relevant, as Chierchia (1992) points out. To illustrate more explicitly, consider the case where a topic is specified and there are 10 actors, with 9 of them each playing one role while the tenth actor plays 10 roles. If all nine actors play their single role well while the tenth actor does not play any of his roles well, then the sentence will come out false. In contrast, if the topic is the actors, then such a scenario will yield a true sentence. The same holds of dou- and ruguo-conditionals as well. It is in fact also possible to get a symmetric reading, if an explicit topic is indicated, say with respect to minimal actor-role pairs. (A scenario that would distinguish the symmetric reading from both asymmetric readings would be one in which some actors may play more than one role, and some roles may each be played by more than one actor.) Though it may be easier to obtain the subject-asymmetric reading in all these cases, we 
assume that this is due to the fact that subjects tend to be taken as the implicit topic in the absence of an overt topic. In the latter two cases ((76)-(77)), this may also be due to the presence of an anaphoric pronoun in the consequent clause.

\section{Comparing with Correlatives}

Although we have analyzed the bare conditionals in Chinese as cases of unselective binding, it has occurred to us that these constructions bear considerable resemblance to the correlative construction in Hindi and other related languages. ${ }^{26}$ To readers familiar with this construction it may have been tempting to assimilate the analysis of bare conditionals to what best accounts for correlatives. We argue here that, in spite of superficial similarities, bare conditionals are not correlatives. We show that they differ in several important respects, which strongly argue for treating them in different ways.

\subsection{Structural Difference}

First of all, note that bare conditionals do not bear any remote structural resemblance to typical relative clauses in Chinese. As is well known, a relative clause in Chinese must be attached to the modification marker $d e$, as shown in (78). Furthermore, the relative clause precedes its head.

$$
\begin{aligned}
& \text { Wo mai-le Jinyong xie *(de) shu } \\
& \text { I buy-ASP Jinyong write DE book } \\
& \text { 'I bought books that Jinyong wrote.' }
\end{aligned}
$$

Chinese also does not have internally headed relatives of the kind found in Navajo, Quechua, Japanese (Platero 1978, Cole 1987, Ito 1986), etc. Finally, although Chinese has the equivalent of a free relative like the ones in what you see is what you get, the syntactic equivalent of this would differ from a headed relative only with respect to the presence of an overt head:

(79) [ni kanjian de [e]] jiushi [ni hui dedao de [e]]
you see DE is you will get $\mathrm{DE}$
'What you see is what you will get.'

${ }^{26}$ We thank Ken Hale for pointing this out to us. 
Of course, the meaning of the sentence can also be expressed with a bare conditional, but it takes on a different form:

(80) ni kanjian shenme, ni jiu hui dedao shenme. you see what you then will get what

'If you see $X$, then you will get $X$.'

In bare conditionals, the relativized marker $d e$ is never present. Further, there is no head NP around. In addition, the consequent clause of a bare conditional may contain the adverb $j i u$ 'then', which is typically used in true conditional sentences. Hence, structurally, bare conditionals are not relative clauses.

\subsection{Tense/Aspect}

Bare conditionals in Mandarin Chinese are very restricted with respect to tense/aspectual specifications. In particular, the verb in the consequent clause cannot bear a completive aspect (as in (81b)). If it bears any element that indicates tense/aspect, it is the future hui 'will' (in 81a)). In contrast, correlatives in Hindi have no such restrictions, as shown in (82).

(81) a. shei lai, shei jiu hui zong jiang who come who then will win prize

'Whoever comes, s/he will win a prize.'

b.*shei lai, shei jiu zong-le jiang who come who then win-ASP prize

(82) jis laRkiiNE ji laRkeKO $\mathrm{j}_{\mathrm{j}}$ dekhaa usNE $\mathrm{usKO}_{\mathrm{j}}$ REL girl-ERG REL bOy-ACC Saw DEM-ERG DEM-ACC passand kiyaa liked

'Which girl saw which boy, she liked him.'

Srivastav (1991)

This contrast follows naturally if bare conditionals in Chinese are genuine conditionals and correlatives in Hindi are genuine relatives. A conditional sentence expresses an if-then relationship between two clauses, and it is typical for the consequent clause to express a situation posterior, rather than anterior, to the situation expressed by the antecedent clause. Such a relation is clearly not required in the case of typical relative clauses, as is evident from the sentence The boy who loves you now used to hate you for a long 
time. Note that this difference also corresponds with the fact that only the bare conditional may take the adverb jiu 'then' in the consequent, but the correlative cannot. Posteriority is a characteristic property of the consequent clause of a conditional sentence, but not a property of a relativized construction.

\subsection{Symmetric vs. Asymmetric Readings}

It has been pointed out by Kadmon (1990) and Heim (1990), among others, that relative clauses and if/when clauses differ in that relative clauses always show asymmetric quantification with respect to the head NP, whereas if/when clauses are more flexible in terms of which head is asymmetrically quantified and can also show symmetric quantification. Thus for the sentence in (83) below, it is impossible to get anything but the subjectasymmetric reading:

(83) Most farmers who own a donkey are rich.

As noted earlier, bare conditionals can have symmetric or asymmetric readings depending on topic selection in discourse. Hence they are similar to if/when clauses. In contrast, in Hindi correlatives, only asymmetric readings can be obtained. Since correlatives in such cases have two relativized head NPs, the asymmetric reading can be with respect to either of them. Crucially, no symmetric reading is available, as the following (from Uptal Lahiri, pers. comm.) shows:

$$
\begin{aligned}
& \text { jo aadmii } i_{i} \text { jis gadhe-ko }{ }_{j} \text { rakhtaa hai vo aadmii } \\
& \text { REL man REL donkey-ACC keeps } \\
& \text { zyaadatar us gadhe-ko poM man } \\
& \text { mostly DEM donkey-ACC beats } \\
& \text { 'Which man keeps which donkey, he mostly beats it.' }
\end{aligned}
$$

There is abundant evidence, then, that bare conditionals are genuine conditionals, and not instances of a "Chinese version" of the correlative construction.

\section{Conclusion}

In this study we have seen that there are two paradigms of donkey sentences in Chinese, which exhibit systematic syntactic differences with respect to the distribution of $w h$-words and anaphoric NPs. We showed that these otherwise puzzling properties find a natural explanation in general, inde- 
pendently motivated principles once they are treated in terms of unselective binding and an E-type analysis, respectively. In line with Heim (1990) we believe that considerations of uniqueness and of the proportion problem do not argue for the adoption of unselective binding in addition to the more traditional E-type analysis. But given the systematic differences observed between the two sentence types in Chinese, there is reason to resurrect the unselective binding mechanism as part of Universal Grammar - though, somewhat ironically, not for the kind of sentences in English that led to Heim's proposal of the mechanism in the first place. We showed that this 'mixed' approach accounts for further differences between the two paradigms with respect to $\forall$ and $\exists$ readings. Finally, we showed that bare conditionals and correlative constructions, though they share certain superficial similarities, must be distinguished and treated as two different species.

An obvious corollary of our paper is that indefinites that are lexically unspecified with respect to their quantificational force can be either variables or true quantifiers, depending on the availability of each use in a context or language, but not on observed quantificational variability alone. Once each use is determined, however, other properties of donkey sentences will follow, as required by independent principles of grammar. Another corollary is that all $w h$-words are not equal in Chinese (contrary to what Aoun and Li (1993) and others assume). Some are unselectively bound, but others are moved (under QR or LF wh-movement). In fact, even exactly the same $w h$-word may or may not be moved at LF, depending on whether it occurs in the environment of a bare, a ruguo- or a dou-conditional. ${ }^{27}$ This conclusion is needed if we assume that quantification is restrictive and non-vacuous, and that it involves a tripartite structure consistently. In the ruguo- and dou-conditionals in particular, a tripartite structure is created by moving a quantifier nuclear scope and mapping its $\mathrm{N}^{\prime}$ onto a restriction (cf. Diesing 1992). The relevant movement may be QR, and possibly $w h$-movement as well, especially in cases of dou-conditionals involving 'why' or 'A-not-A' that do not have a non-interrogative interpretation.

27 The determining factor is clearly not whether a given $w h$-word is D-linked or non-Dlinked in the sense of Pesetsky (1987). 


\section{REFERENCES}

Aoun, Joseph and Audrey L1 1993, 'Wh-Elements in Situ Syntax or LF?', Lingulstic Inquiry 24, 199-238

Berman, Stephen 1987, 'Situatıon-based Semantics for Adverbs of Quantification', in University of Massachusetts Occasional Papers 12, pp 45-68

Chao, Wynn and Peter Sells 1983, 'On the Interpretation of Resumptive Pronouns', in $\mathrm{P}$ Sells and C Jones (eds), Proceedings of NELS 13, GLSA, University of Massachusetts, Amherst, pp 47-61

Cheng, Lisa L S 1991, On the Typology of Wh-Questions, Ph D dissertation, MIT

Cheng, Lisa L S 1995, 'On Dou-quantification', Journal of East Astan Lingutstics 4(3), 197-234

Chierchia, Gennaro 1992, 'Anaphora and Dynamic Bindıng', Lingutstics and Philosophy 15, 111-183

Chomsky, Noam 1976, 'Conditions on Rules of Grammar', Lingu'stic Analysts 2(4), 303-351

Cole, Peter 1987, 'The Structure of Internally Headed Relative Clauses', Natural Language and Linguistic Theory 5, 277-302

Cooper, Robin 1979, 'The Interpretation of Pronouns', Syntax and Semantics 10, 61-92

Diesing, Molly 1992, Indefinites, MIT Press, Cambridge, Mass

Engdahl, Elısabet 1986, Constituent Questions, Kluwer, Dordrecht

Evans, Gareth 1980, 'Pronouns', Lingutstic Inquiry 11(2), 337-362

von Fintel, Ka1 1994, Restrictions on Quantifier Domains, Ph D dissertation, University of Massachusetts, Amherst

Hamblın, C L 1973, 'Questions in Montague Englısh', Foundations of Language 10, 41-53

Heim, Irene 1982, The Semantics of Defintte and Indefinte Noun Phrases, Ph D dissertatıon, University of Massachusetts, Amherst

Heim, Irene 1990, 'E type Pronouns and Donkey Anaphora', Lingutstics and Philosophy 13, 137-178

Higginbotham, James 1980a, 'Pronouns and Bound Variables', Linguistıc Inquiry 11, 679-708

Higgınbotham, James 1980b, 'Anaphora and GB Some Prelımınary Remarks', in J Jensen (ed ), Proceedings of NELS 9, pp 223-236

Higginbotham, James 1985, 'On Semantics', Lingulstic Inquiry 16(4), 547-593

Huang, C -T James 1982, Logical Relations in Chinese and the Theory of Grammar, Ph D dissertation, MIT

Huang, C T James 1984, 'On the Distribution and Reference of Empty Pronouns', Lingulstic Inquiry $15,531-574$

Huang, C -T James 1987, 'Exıstentral Sentences in Chınese and (In)definiteness', in E J Reuland and A G B ter Meulen (eds), The Representation of (In)definiteness, pp 226-253 MIT Press

Ito, Junko 1986, 'Head Movement at LF and PF' in Untversity of Massachusetts Occasional Papers in Linguistics 11, pp 109-138

Kadmon, Nirit 1987, On Unique and Non-Unique Reference and Asymmetric Quantification, $\mathrm{Ph} \mathrm{D}$ dissertation, University of Massachusetts, Amherst

Kadmon, Nirıt 1990, 'Uniqueness', Linguistics and Philosophy 13, 273-324

Kamp, Hans 1981, 'A Theory of Truth and Semantic Representation', in J Groenendıjk, T Janssen, and M Stokhof (eds ), Formal Methods in the Study of Language, Mathematical Centre Tracts, Amsterdam, pp 277-322

Karttunen, Laurı 1977, 'Syntax and Semantics of Questions', Lingutstics and Philosophy $1,3-44$

Koopman, Hilda and Dominique Sportıche 1982, 'Variables and the Bijection Principle', The Linguistics Review 2, 139-160

Kratzer, Angelıka 1986, 'Conditionals', Chicago Lingutstıc Socıety 22(2), 1-15 
Kratzer, Angelika 1989, 'Indıvıdual-level vs Stage-level Predicates', in E Bach, A Kratzer, and B Partee (eds ), Papers on Quantification, University of Massachusetts, Amherst

Lahir,, Utpal 1991, Embedded Interrogattves and Predicates That Embed Them, $\mathrm{Ph} \mathrm{D}$ dissertation, MIT

Lewis, David 1975, 'Adverbs of Quantıfication', in E Keenan (ed ), Formal Semantics, Cambridge University Press, Cambridge

L1, Xıao-guang 1994, 'Dou as Event Quantıfıer', ms, University of Calıfornia, Irvine

Li, Y -H Audrey 1992, 'Indefinite Wh in Mandarin Chinese', Journal of East Asian Lingutstics 1(2), 125-156

Lu, Shu Xıang 1980, Xlandal Hanyu Babal Cl (Elght Hundred Words in Modern Chinese), Commercial Press, Beijng

Montalbett1, Mario M 1984, After Binding, On the Interpretation of Pronouns, Ph D dissertation, MIT

Neale, Stephen 1991, Descriptions, MIT Press, Cambridge, Massachusetts

Nishigauchi, Taisuke 1990, Quantıfication in the Theory of Grammar, Kluwer, Dordrecht

Parsons, Terry 1978, 'Pronouns as Paraphrases', ms , University of Massachusetts, Amherst

Pelletier, Francis J and Lenhart K Schubert 1989, 'Generically Speakıng, or Usıng Discourse Representation Theory to Interpret Generics', in G Chierchia, B H Partee, and $\mathrm{R}$ Turner (eds ), Properties, Types and Meaning, vol 2, Kluwer, Dordrecht

Pesetsky, David 1987, 'Wh-1n situ Movement and Unselectıve Bindıng,' in E J Reuland and A G B ter Meulen (eds), The Representation of (In)defintteness, MIT Press, Cambridge, Mass

Platero, Paul 1978, Missing Noun Phrases in Navajo, Ph D dissertatıon, MIT

Safir, Ken 1985, Syntactıc Chains, Cambridge Unıversity Press

Sells, Peter 1984, Syntax and Semantics of Resumptive Pronouns, Ph D dissertation, University of Massachusetts, Amherst

Srivastav, Veneeta 1991, 'The Syntax and Semantics of Correlatives', Natural Language and Linguistic Theory 9, 637-686

Tsa1, Wel-Tien 1994, 'To Move or Not to Move, That Is the Question', paper presented in Theoretical East Asıan Linguistics Workshop, UC Irvine, January 1994

Yu, X 1 Liang 1965, 'Yıwen daicı de renzhı yongfa' (On the "wh-ever" use of interrogative pronouns), Zhongguo Yuwen 1, 30-35

Zaefferer, Dietmar 1990, 'Conditionals and Unconditionals in Universal Grammar and Situation Semantics', in R Cooper, K Muka1, and J Perry (eds), Situation Theory and Applications 1, CSLI, Stanford, pp 471-492

Department of Linguistics

University of Californı

Irvine, CA 92717, U S A

llcheng@uc1 edu

Jhuang@uc1 edu 

. 
For information about current subscription rates and prices for back volumes for Natural Language Semantics, ISSN 0925-854X

please contact one of the customer service departments of Kluwer Academic Publishers or return the form overleaf to:

Kluwer Academic Publishers, Customer Service, P.O. Box 322, 3300 AH Dordrecht, the Netherlands, Telephone (+31) 78524 400, Fax (+31) 78183273 , Email: services@ wkap.nl

or

Kluwer Academic Publishers, Customer Service, P.O. Box 358, Accord Station, Hingham MA 02018-0358, USA, Telephone (1) 617871 6600, Fax (1) 617871 6528, Email: kluwer@world.std.com

\section{Call for papers}

Authors wishing to submit papers related to any of the themes or topics covered by Natural Language Semantics are cordially invited to prepare their manuscript following the 'Instructions for Authors'. Please request these instructions using the card below.

\section{Author response card}

\section{Natural Language Semantics}

I intend to submit an article on the following topic:

Please send me detailed 'Instructions for Authors'.

NAME

INSTITUTE

DEPARTMENT

ADDRESS

Telephone

Telefax

Email

\section{Library Recommendation Form}

Route via Interdepartmental Mail

To the Serials Librarian at:

From: Dept./Faculty of:

Dear Librarıan,

I would like to recommend our library to carry a subscription to

Natural Language Semantics, ISSN 0925-854X

published by Kluwer Academic Publishers. 
Request for information about current subscription rates and prices for back volumes of

\section{Natural Language Semantics, ISSN 0925-854X}

Please fill in and return to:

Kluwer Academic Publıshers, Customer Service, P.O. Box 322, 3300 AH Dordrecht, the Netherlands

Kluwer Academic Publishers, Customer Service, P.O. Box 358, Accord Station, Hingham MA 02018-0358, USA

Please send information about current program and prices

Please send a free sample copy

\section{NAME}

INSTITUTE

DEPARTMENT

ADDRESS

Telephone

Telefax

Emall

Natural Language Semantics

Kluwer Academic Publishers,

P.O. Box 17

3300 AA Dordrecht

The Netherlands

TO : The Library

FROM: 